\title{
The Asset Liability Management in Italian Public Entities
}

\author{
G. Fantini
}

\begin{abstract}
Modern management of Public Entities is turning increasily to Asset Liability Management. This management can be effectively realized by a set of operations that can be defined as "Debt Restructuring". Financial innovative instruments are playing an increasing role with respect to current debt or will be activated in the near future. Derivatives - such as swaps - and structured finance transactions - such as securitization and project finance -are of considerable importance. The paper analyses the economic effects produced in their accounts and provides useful insights for future administrative regulations regarding acceptable operation for PE.
\end{abstract}

Index Terms-Asset liability management, derivatives, public entities.

\section{INTRODUCTION}

The topic of the financial derivatives underwriting has been in the spotlight for several years. This is also the case for Public Entities (PE) because interest rates have been very volatile as a result of the financial crises; these instruments have produced large financial flows often with considerable impact on the management of PEs. On March 31st, 2012 the Public Entities with negative value of derivative contracts above the threshold of detection of the Central Credit Risk were 214 (Central Credit Risk threshold: $€ 30.000$ from January 2009, before that date $€ 75.000$ ), fewer if this number is compared to those values registered at the end of 2010 and 2011 (respectively 309 and 233). As revealed by the press, the use of derivative instruments for Public Entities such as Interest Rate Swaps in certain cases had a speculative and / or short term hedging aim. Their use in the management of those PEs, who subscribed to them, in certain cases produced significant problems regarding current and future imbalance deriving from: i) dispensing of high "up-front", used to balance current management operations and not for the financing of investments, ii) too low thresholds "knock-out" compared to the evolution of the monetary parameter chosen in the short and medium term, iii) very high spread and implicit transaction costs to the benefit of all financial intermediaries, iv) strongly negative initial "mark to market" operations.

The objective of this research, after a discussion of the most common forms of derivative contracts entered into by the Public Entities, is to investigate the economic effects produced by these instruments in the financial statements of these institutions.

Manuscript received March 22, 2013; revised June 3, 2013.

G. Fantini is with the Università degli Studi di Ferrara (e-mail: giulia.fantini@unife.it).

\section{DEFINITION AND USE}

As shown in the applicable legislation [1]-[3], derivatives are contracts whose value is derived from (depends on) the price of an underlying financial asset, or the value of a reference parameter (stock index, interest rate, exchange rate). In literature, some authors point out that the complexity of these products can be identified in the determination of contract "cash flow based on an underlying or specific assets, securities, rate or index." In the same way, the definition given by the Italian Stock Exchange of financial derivatives is very clear, a "financial instrument is defined as a derivative financial instrument because its cost/performance profile depends on the cost/performance parameters of other main instruments, the "underlying" - which can be: raw materials, currencies, interest rates, stocks, stock indices". So we can say that the value of a derivative instrument is pre-fixed in relation to the value of a specified real good or financial asset (underlying) whose price (spot price) is formed on the relevant market.

The use of these instruments can have different purposes: from hedging, whose aim is embodied in the desire to reduce the financial risk of a pre-existing portfolio, to speculation, whose aim is to gain exposure to risk in order to achieve a profit, or arbitrage which is basically the desire to make a profit without risk through transactions on the derivative and the underlying combined to take advantage of any such valuation differences. Therefore the instruments in question are not in themselves "negative ", but they present some complexity profiles that make them sometimes difficult to understand and evaluate. In particular, the more complex problems are certainly due to the determination - or rather the valuation - of their value. In theory, the value of the derivative depends on the relations that link the different variables involved to the expected result from the derivative itself. This result is called "pay-off". In particular, their estimation requires the ability to simulate possible future scenarios concerning the relationship between the underlying and other variables in order to determine the expected value of the pay-off. Therefore, the value of the derivative is the average of the values of the payoffs weighed by the probability of each scenario (greater weight will be given to the most likely scenarios), discounted by the time value (i.e. reported at the time of evaluation).

\section{LegisLATION}

In Italy there is a specific legal framework for the financial derivative transactions carried out by Public Entities, it is the legislative result of a rather and troubled evolution over the last two decades.

Since 1996 Italian Public Entities have been able to use 
swap to cover themselves against currencies fluctuations this was allowed by the Law 539/1995.

During the following years substantial changes in the use of these instruments have been made by Italian Public Entities.

Below the key points are identified:

Law 724/1994, eliminated the Cassa Depositi e Prestiti monopoly regime as regards the credit operating activities in favor of the Regions, Provinces and Municipalities (in force since the late seventies). In addition, it also regulated the possibility for the PE to have a direct access to the capital market through the issue of bonds with capital installments amortization (called "amortizing"), but with the exception of event-linked bonds i.e. "Bullet" (obligations in which the principal repayment is made in a lump sum at maturity).

Law 448/2001 art. 41, introduced some innovations compared to previous legislation through expanding PE access in capital markets and allowing them the possibility to negotiate derivatives. This law for the first time attributed power to the PE to issue bonds with repayment of principal and interest in full at maturity. The PEs who wanted to use an emission "bullet" were therefore liable to constitute a sinking fund, whose aims were to distribute the burden of repaying the bonds evenly among exercises, or - alternatively - to negotiate a swap with a financial intermediary to replace the repayment of principal in a lump sum with depreciation. Furthermore, the same article made reference to other possible financial derivative transactions, postponing the adoption of regulations "relating to the amortization of the debt and the use of derivatives by the technical PE to a Decree of the Ministry of Economy and Finance".

Decree 389/2003 of December 1st, $2003 \mathrm{n.389}$, this intervention regulated the coordination procedures for the access to capital markets by the PE, and confirmed the possibility - under certain conditions - to make transactions in Interest Rate Swaps (IRS). First of all, the subject of the derivative contract had to be designed such as "Plain Vanilla", i.e. the simplest model that enables the exchange flows of interest rates. The basic structure of the derivative could be complemented by the purchase of a "cap" or "floor" or both ("collar"). The up-front could not be more than $1 \%$ of the notional principal of the underlying liabilities and interest rates - taken as a reference - had to be hooked to the monetary parameters in use in the countries belonging to the group of the seven most industrialized countries and these could not hold levers or multipliers. The IRS could be only achieved in the presence of liabilities actually due It was not possible to carry out derivative transactions making reference to other existing derivative transactions and, in the event of changes in liability underlying the instrument, conditions that would prevent the PE from suffering a loss would be adopted. Finally the intermediaries had to have an adequate rating assigned by agencies recognized internationally. The intent of the provisions set was twofold: on the one hand to reduce the risk exposure associated with the evolution of financial markets, on the other hand to avoid the possibility of translating the financial burden of outstanding transactions on future periods. The law required that derivative contracts were not to pursue speculative aims and, therefore, they were designed to contain "only" the risk linked to the increase in interest rates or to reduce the cost of debt at fixed rates. Until a few years ago, there was a growth of the use of derivative instruments, linked to the need to put in place restructuring operations of mortgages or other types of loans, with the aim of lengthening maturities and reducing the installments of amortization (for the renegotiated contracts). However the renegotiations often included conditions unfavorable for PE or implied additional risks. These additional risks meant that PEs had only a very remote chance of being able to reap the benefits in terms of risk protection against interest rates fluctuations. Moreover, in some cases the intermediary anticipated to PE the amount of money required to close the old contract (or even an additional amount in cash), while the $\mathrm{PE}$ reimbursed this amount through future payments on more onerous terms than those set out in a normal derivative contract entered into "equal". These were highly speculative operations in which the PEs reduced the cost of debt, but at the cost of increased risk in subsequent years and postponed payments creating a form of hidden debt for future generations.

Before the MEF 2003 Decree allowing the use of a derivative came into force it was necessary for the PE to envisage its use within accounting regulations. These accounting regulations were also to specify the limit of operations to cover the risks related to the volatility of interest rates or the concentration of its debt in some type of rate and the explicit prohibition of engaging in speculative transactions.

Finanziaria 2007 (art. 1 paragraph 736), specified that the operations of debt management through the use of derivatives should be characterized by the reduction of the final cost of debt and the level of exposure to market risks. The PE could enter into such transactions only at those liabilities currently due. With the coming into force of this article PE were obliged to give assurance that at the base of their choice to subscribe to these instruments there was the likelihood of increased stability in the budget in terms of a lower final cost of operations, These lower final costs were to be assessed in terms of the balance between total cost and market risk. The same article stated that these contracts had to be transmitted by PE to the MEF (Ministry of Economy and Finance). This transmission was to take place before their subscription under the penalty of their effectiveness.

Finanziaria 2008, subordinated the use of derivatives to the maximum transparency and publicity in the reporting of financial statements. But with the three-year 2008 financial manoeuvre the use of these instruments by the PE was initially entirely suspended while awaiting a measure of reorganization of this discipline. With the same financial manoeuvre the PE were banned from making recourse to the borrowing type bullet and finally there were plans to include the up-front between borrowing transactions in the financial statement.

Finanziaria 2009, confirmed the block on PE signing new derivative contracts until the MEF regulations [4] came into force, but at the same time it allowed them the opportunity to restructure their existing derivative contracts which, as a result of changes in the underlying liabilities do no longer represent effective hedging transactions. This confirmed the ban on PEs issuing bonds repayable in one installment (the 
"bullet". Finally, the law established that under the penalty of nullity of the contract, the derivative transactions entered after its entry into force must provide a specific statement in the contract as well as certification by the administrator of the Public Entity certifying that he has acquired a full understanding of the nature of the instrument and its effects on the budget. The invalidity of the contract may only be brought by the PE. In any case, waiting for a reorganization of the regulations, the PE cannot enter into new derivative contracts. Compliance with the rules concerning the form and the content of contracts as indicated by the Ministry of Economy and Finance as well as the evidence of understanding of the risks and characteristics of the contracts are presented as elements of the contract, in the absence of whom the agreement cannot be considered completed. The Court of Auditors shall be informed when contracts are concluded in breach of the rules contained in the law.

The greater freedom of access to the financial resources and more stringent budgetary constraints introduced the PE to adopt more sophisticated forms of management of liabilities. Therefore, there are two main factors that have prompted the strong growth of the use of derivatives by these institutions: i) increased collection on the bond market through the issuance of bonds that they provided for the repayment of principal in full at maturity (in finance there are known as "bullet"), ii) a more active debt management, based on the restructuring and extension of maturities.

\section{ACtive Management AND the AsSet Liability MANAGEMENT}

The PE should follow the mandatory constraint imposed by the Internal Stability Pact (PSI) in the preparation and management of the budget. Its aim - related to the PE - is the progressive reduction of the deficit financing of expenditure and the relationship between debt and gross domestic product (GDP). Is possible to assert that the PSI has two main concerns: $i)$ the high share of public expenditure managed by local governments that affect fiscal consolidation objectives, ii) the resulting connection to the commitments of the Stability and Growth Pact of the central government. So, the PSI intent represents the will of the State to involve the PE in the fiscal consolidation by controlling their net debt with the definition of objectives that these entities must pursue during the year. As a result of the current context, the management of $\mathrm{PE}$ is necessarily based on maximum prudence and efficiency, criteria within the so-called asset liability management (ALM). In this context, every management decision should be evaluated and monitored carefully and consistently in accordance with the objectives of limiting the risk and cost containment. Falling into this category are: i) the set of operations that, in general, can be defined as the "Debt Restructuring", ii) Asset Liability Management, a methodology for the management of financial items, which takes into account both the aspect of risk management and the time horizon.

The "Debt Restructuring" aims to enable the PE to alter its debt positions in order to take advantage of specific market conditions in order to achieve economic benefit that frees resources in the budget. Tools that enable the restructuring of the debt are of two categories:

- Traditional instruments (which are concerned with the management of the remaining debt), in which we can identify the renegotiation and early termination,

- Innovative instruments (which may relate to or be applicable to both current debt and debt which will be activated in the near future) derivatives, securitization and project financing fall into this category.

The IRS (Interest Rate Swap) can be included in the latter category above mentioned. They are normally used as hedging instruments to reduce/offset the exposure to interest rate risk. These may allow the optimization of the cost of debt, the maximization of return on investment and the maintaining of a sustainable balance between sources and uses in order to minimize the risks.

Asset Liability Management seeks, in the same way, to achieve a stabilization of the financial balance in order to reduce the overall level of risk. This is done through a temporal correspondence between the cash flows generated by the assets and the cash flows generated by liabilities in a way that does not create situations of illiquidity. It is important to specify that the management of passive is based on diversification (i.e. on the choice of the combination of its debt in such a way that it is possible to minimize the risks related to various stages of monetary policy, in order to decrease the volatility of flows for interest). Diversification may involve indexing, maturity and currency or the reduction of supply risks (roll-over). The first step of integrated management includes the analysis of the reactivity of balance sheet items to changes in the interest rate market in relation to a fixed period of time, and then determines PE risk exposure at the present time. This risk exposure depends critically on the term structure of interest rates of assets and liabilities. Finally, the debt structure can be modified by the use of financial derivatives.

\section{ACCOUnTABILITY AND Flows USE}

All events generated by these operations have a non-negligible impact on the PE budgets particularly in terms of up-front, netting positive and negative mark-to-market (MtM).

In this regard it should be noted that the budget of the PE can be divided into two parts, on one side we have the current management and on the other side we have the investment. Each party in turn is divided into revenues and current expenditure and capital expenditure.

Current expenditure can only be financed through revenue recognized from Title I to Title III., while the investment costs can only be financed through the use of revenues entered from the Title IV to VI. Therefore, only a portion of the administrative surplus is the only way of connection between capital expenditure and current revenues.

The PEs suffers pressure especially in terms of current expenditure. That is due to the fact that they do not have the necessary revenues to cover current expenses. Therefore the use by the PE of these types of instruments derives from their need to find sources to enable them to finance these costs. The decision to subscribe bullet loans is therefore instrumental in attempting to solve a problem of financial 
stress.

\begin{tabular}{|c|c|c|c|}
\hline \multicolumn{2}{|r|}{ REVENUES } & \multicolumn{2}{|c|}{ EXPENDITURE } \\
\hline Title $\mathbf{I}^{\circ}$ & Tax Revenues & Title $\mathbf{I}^{\circ}$ & $\begin{array}{l}\text { Current } \\
\text { Expenditure }\end{array}$ \\
\hline Title $\mathbf{I I}^{\circ}$ & Current Transfers & 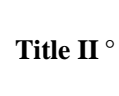 & $\begin{array}{l}\text { Capital } \\
\text { Expenditure }\end{array}$ \\
\hline Title III $^{\circ}$ & Extra Tax Revenues & Title III $^{\circ}$ & $\begin{array}{l}\text { Loan } \\
\text { Repayment }\end{array}$ \\
\hline Title IV $^{\circ}$ & $\begin{array}{l}\text { Alienation of property, } \\
\text { Credit collection }\end{array}$ & & \\
\hline Title $\mathbf{V}^{\circ}$ & Loans & & \\
\hline Title $V I^{\circ}$ & Contract Services & Title $\mathbf{I V}^{\circ}$ & $\begin{array}{l}\text { Contract } \\
\text { Services }\end{array}$ \\
\hline
\end{tabular}

The up-front represents the premium received by the PE at the conclusion of derivative transactions. Normally it would be considered an extraordinary item and allocated under Title IV of the budget revenues; therefore it could not be used to cover current expenditure.

The negative netting, on the contrary, must be considered current expenditure and is enrolled in Title I of the expenditures. If, on the other hand the netting is positive and refers only to interest, its proper place is in the title III of the revenues. Alternatively - in accordance with the principle of prudence - it could be recorded in the aforementioned title IV of revenues; and as mentioned, for the up-front, positive netting being capital revenues cannot be used to cover current expenses.

The mark to market is not expected in the PE accounting system. It represents a future flow that will be generated at maturity, so it cannot be highlighted during the life of the derivative contract, except as a potential loss or a potential gain - which is rarely covered in the budgets of the EL. However, from a responsible interpretation of paragraph 383 of the Finanziaria 2008, it is clear that the budget should be accompanied by a note reporting the differential flows that have been generated from the stipulation, the potential flow for the next three years, the quarterly basis MtM and the status and the trend of the financial operation.

The problem is that in the PE Prevision Budget and expenditure account the following information should be reported; the up-front received, the value of the MtM both when the contract was subscribed and at the Budget date, the positive and negative nettings, and a prospective analysis related to the expected cash flow risk.

\section{THE RELEVANCE OF THE PHENOMENON}

To understand how widespread this phenomenon is, refer to the Bank of Italy Annual Report 2011 [5] which makes specific mention of the number of PE who are involved in financial derivative operations with banks operating in Italy.
The table a13.15 Bank of Italy Annual Report 2011 shows their exposure in financial derivative instruments from 2007 to March 2012, highlighting the notional amount and negative and positive mark to market value - in the PE point of view.

At first it should be noted that the total number of PE involved from 2007 onwards has suffered a sharp decline from 671 to 233 . It is possible to attribute this gradual reduction, in the use of these instruments, to the following factors: i) a ban imposed in 2008 on PE preventing them from entering into new derivative contracts until the reorganization of the regulation, ii) the early closure of some hedges in place.

The regions with the highest number of PE involved in financial derivatives are Lombardy first, Campania second and Sicily third.

Referring to the negative mark to market, during the period 2007 - March 2012, a significant increase was registered from 902 million Euros to 1,217 million Euros. At the same time the notional value of these instruments was nearly halved, from 31,520 million Euros to 11,662 million Euros.

\section{CONCLUSION}

The above analysis shows that from 2007 to March 2012, the PE exposure in terms of notional value, almost halved. This is attributable to two factors, the prohibition imposed by Finanziaria 2008 and the early closure of some hedges in place. At the same time the number of derivatives that were signed by PE, in the same time period, decreased from 671 to 214.

In some cases these instruments were adopted by PE with the aim of ensuring the trend in interest rates on mortgages that were in place with the Cassa Depositi e Prestiti or other financial institutions (such transactions were permitted by law and are non-speculative), while in other cases the intent was due to the needs of PE to have more liquidity within the municipal coffers in order to meet the current expenditure.

The problem is that nowadays there is a lack of legislation relating to the reporting of cash flows generated by these instruments and PEs, in their budget, do not have to provide detailed information about these instruments.

\section{REFERENCES}

[1] Bank of Italy Regulation on July 2nd, 1991, art. 49 - a), b), c), d), e), g), h).

[2] Bank of Italy Circular on July 23rd, 1994.

[3] F. C. Nassetti, "I contratti derivati finanziari," Giuffrè, Milano, 2007, pp. 1-3, pp. 719-722

[4] Ministero dell'Economia e delle Finanze. (2008). Schema di regolamento ministeriale di attuazione dell'articolo 62 del decreto legge 25 giugno. Convertito con modificazioni dalla legge 6 agosto, come sostituito dall'articolo 3 della legge 22 dicembre. Documento in consultazione. (September 22nd, 2009). [Online]. Available: http://www.dt.tesoro.it/export/sites/sitodt/modules/documenti_it/regol amentazione_bancaria_finanziaria/consultazioni_pubbliche/Derivati_ enti_locali_-_regolamento_ex_articolo_62_d.1.pdf

[5] Bank of Itay. (May 2012). Relazione Annuale - Presentata all'Assemblea Ordinaria dei Partecipanti. Table a13.15: Amministrazioni locali: operazioni in derivati finanziari con banche operanti in Italia. [Online]. pp. 118. Available: http://www.bancaditalia.it/pubblicazioni/relann/rel11/rel11it/appendic e/app11_13_finanza_pubblica.pdf 


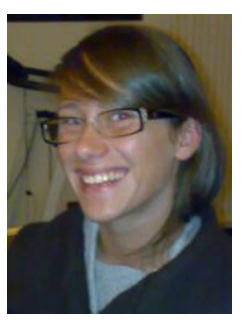

G. Fantini was born in Italy on March 29, 1985. She is a Ph.D Student ( $3^{\text {rd }}$ year) at the University of Ferrara, Department Economics and Management. Now she is a Visiting Ph.D Student at Cass Business School Department of Finance, until the end of July 2013. In 2009 she received MSC in Business Administration, Management and Professions at the University of Ferrara - thesis: "IRS in Public Administrations: objectives and pathology". In 2007 she received a BA in Economics, Management and Financial Intermediates at the University of Ferrara - thesis "Mergers and acquisitions between banks: recent Italian experiences" Main work experiences: October 2012 - February 2013 she was a trainee at ESPON CU in the Cluster Business and Finance in Luxembourg, where she was involved in different tasks related to finance risk management and audit. On May 2012 after 3 years as a Accounting Practitioner, (from February 2008 until February 2011 in Italy) - she became a Business Consultant (Dottore Commercialista ed Esperto Contabile) and Statutory Audit (Revisore Legale). Conferences: on June 2012 she participated in the Doctoral Session at the "V Convegno Nazionale di Azienda Pubblica" where she presented the paper "Asset Liability Management in Italian Public Entities". Fellowship: during her undergraduate studies BA - 2005/2006, she won the ERASMUS scholarship that allowed her to spend 9 months in Spain. 